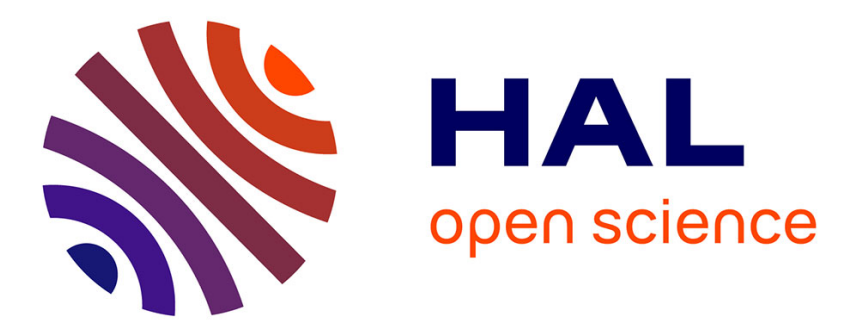

\title{
Transmission of different variants of PCV2 and viral dynamics in a research facility with pigs mingled from PMWS-affected herds and non-affected herds
}

\author{
K. Dupont, C.K. Hjulsager, C.S. Kristensen, P. Baekbo, L.E. Larsen
}

\section{- To cite this version:}

K. Dupont, C.K. Hjulsager, C.S. Kristensen, P. Baekbo, L.E. Larsen. Transmission of different variants of PCV2 and viral dynamics in a research facility with pigs mingled from PMWS-affected herds and non-affected herds. Veterinary Microbiology, 2009, 139 (3-4), pp.219. 10.1016/j.vetmic.2009.06.001 . hal-00526931

\section{HAL Id: hal-00526931 \\ https://hal.science/hal-00526931}

Submitted on 17 Oct 2010

HAL is a multi-disciplinary open access archive for the deposit and dissemination of scientific research documents, whether they are published or not. The documents may come from teaching and research institutions in France or abroad, or from public or private research centers.
L'archive ouverte pluridisciplinaire HAL, est destinée au dépôt et à la diffusion de documents scientifiques de niveau recherche, publiés ou non, émanant des établissements d'enseignement et de recherche français ou étrangers, des laboratoires publics ou privés. 


\section{Accepted Manuscript}

Title: Transmission of different variants of PCV2 and viral dynamics in a research facility with pigs mingled from PMWS-affected herds and non-affected herds

Authors: K. Dupont, C.K. Hjulsager, C.S. Kristensen, P. Baekbo, L.E. Larsen

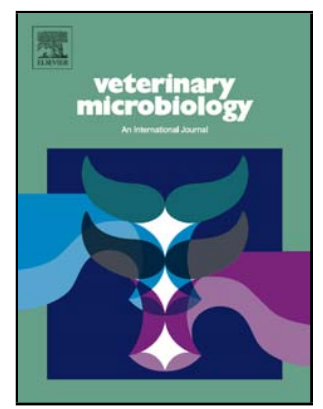

PII: S0378-1135(09)00285-5

DOI: doi:10.1016/j.vetmic.2009.06.001

Reference: VETMIC 4455

To appear in: $\quad$ VETMIC

Received date: $\quad 27-10-2008$

Revised date: 27-5-2009

Accepted date: $\quad 3-6-2009$

Please cite this article as: Dupont, K., Hjulsager, C.K., Kristensen, C.S., Baekbo, P., Larsen, L.E., Transmission of different variants of PCV2 and viral dynamics in a research facility with pigs mingled from PMWS-affected herds and non-affected herds, Veterinary Microbiology (2008), doi:10.1016/j.vetmic.2009.06.001

This is a PDF file of an unedited manuscript that has been accepted for publication. As a service to our customers we are providing this early version of the manuscript. The manuscript will undergo copyediting, typesetting, and review of the resulting proof before it is published in its final form. Please note that during the production process errors may be discovered which could affect the content, and all legal disclaimers that apply to the journal pertain. 


\title{
Transmission of different variants of PCV2 and viral dynamics in a research
}

\section{facility with pigs mingled from PMWS-affected herds and non-affected herds}

\author{
K. Dupont ${ }^{\mathrm{a}^{*}}$, \\ C. K. Hjulsager ${ }^{\mathrm{a}}$, C. \\ C. S. Kristensen ${ }^{\mathrm{b}}$, P. Baekbo ${ }^{\mathrm{b}}$, \\ E. Larsen ${ }^{\mathrm{a}}$
}

${ }^{a}$ National Veterinary Institute, The Technical University of Denmark, Denmark

${ }^{b}$ Danish Pig Production, Kjellerup, Denmark

8

* Corresponding author. Tel.: +45 35886258; fax: +45 72346340

E-mail address: kidu@vet.dtu.dk (K. Dupont).

Keywords: PCV2, PMWS, horizontal transmission, sequencing, real-time PCR, quantification.

Abstract

Postweaning Multisystemic Wasting Syndrome (PMWS) has been identified in most swineproducing countries worldwide. The disease has resulted in significant health challenges and economic damage to the swine industry. The aim of this study was to determine horizontal transmission of porcine circovirus type 2 (PCV2) and to examine viral dynamics in pigs in a controlled PMWS transmission study. In the study pigs from PMWS-affected herds and nonaffected herds were permitted to have close contact (same pen), nose-to-nose contact (to pigs in neighbouring pens) or no physical contact (pen across the aisle and pens in other compartments).

1 By DNA sequence analysis, eight variants of genotype PCV-2b were identified in the research 2 facility. From the spread of these PCV2-variants it was concluded that PCV2 primarily infects 3 through direct contact and nose-to-nose contact. PCV2 genome sequences were obtained from 4 selected pigs at arrival to the research facility and again when the same pigs developed PMWS. 
1 This analysis showed that pigs from PMWS-affected herds developed PMWS caused by the same variant of PCV2 as they carried when entering the research facility. In contrast, pigs from nonaffected herds developed PMWS with PCV2-variants identified in pigs from PMWS-affected herds. This was probably connected to at least $10^{3}$ higher mean serum-titer of PCV2 in pigs from PMWSaffected herds as compared to pigs from non-affected herds at the beginning of the transmission study. The study further showed that pigs able to control the PCV2-infection, as measured by the PCV2-titer in serum, recovered clinically (pigs from PMWS-affected herds) or stayed healthy (pigs from non-affected herds). Like this, pigs with a PCV2 titer below $5 \times 10^{8}$ copies $/ \mathrm{ml}$ serum during the study period had a chance of recover from the PCV2 infection whereas pigs with PCV2 titers above $5 \times 10^{8}$ copies $/ \mathrm{ml}$ serum at any time point generally died from PMWS.

\section{Introduction}

Post-weaning Multisystemic Wasting Syndrome (PMWS) was first observed in Canada in 1991 (Harding and Clark, 1997). It has today a worldwide distribution and is considered one of the most important swine diseases in Europe. Usually PMWS appears in pigs aged two to four months. Affected pigs show wasting or unthriftiness, enlarged lymph nodes, respiratory distress and occasionally jaundice and diarrhea (Segalés et al., 2005a). The most distinct microscopic lesions in lymphoid organs are lymphoid cell depletion as well as formation of multinucleated giant cells and basophilic intracytoplasmic inclusion bodies (Segalés and Domingo, 2002). Infection with PCV2 is needed for full expression of PMWS. However, not all pigs infected with PCV2 will develop the disease (Segalés et al., 2005a).

Infection with PCV2 is systemic (Bolin et al., 2001; Brunborg et al., 2004) with a higher viral load in serum and tissues of pigs suffering from PMWS as compared to healthy pigs (Brunborg et al., 
1 2004; Liu et al., 2000; Olvera et al., 2004; Rovira et al., 2002; Segalés et al., 2005b). The

2 respiratory system may be the route of entry, as suggested by the capacity of the virus to infect

3 bronchial and bronchiolar epithelial cells (Magar et al., 2000). Alternatively or complementary,

4 PCV2 may infect the nasopharynx and tonsils and spread via the blood or lymph (Magar et al.,

5 2000). PCV2 has also been detected in bronchial, nasal, tonsillar, salivary, ocular, faecal and

6 urinary swabs (Bolin et al., 2001; Krakowka et al., 2000; Segalés et al., 2005b; Shibata et al., 2003;

7 Grau-Roma et al., 2008b), again with a significant higher viral load in secretions from PMWS-

8 affected pigs (Segalés et al., 2005b; Grau-Roma et al., 2008b). This suggests that oro-nasal

9 secretions as well as urine and faeces are potential routes of viral shedding.

10 The incubation period for development of PMWS is approximately two weeks (Albina et al., 2001).

11 Interestingly, when PCV2-inoculated piglets were placed in contact with specific pathogen-free

12 (SPF) piglets, disease in the contact-exposed SPF piglets was recorded 16 days after appearance of

13 clinical signs in the inoculated pigs. This observation suggests that the contact-exposed SPF piglets

14 became infected during the clinical phase of the inoculated piglets (Albina et al., 2001) where the

15 viral load in secretions is expected to be high. PCV2 is able to persist in the pigs for a long period.

16 Thus, infectious PCV2 viruses were detected in tissues of a single pig sacrificed at day 125 post-

17 infection (Bolin et al., 2001). In blood and secretions, virus has been detected until post-infection

18 day 70, the day of necropsy (Bolin et al., 2001). The long persistence of virus in secretions enables

19 transmission of virus for a long period. Hence, direct contact with pigs carrying a 42-days old PCV2

20 infection resulted in transmission of virus to 3 of 3 control pigs (Bolin et al., 2001).

21 PMWS commonly affects pigs 2-3 weeks after weaning (Harding and Clark, 1997) suggesting that

22 natural infection occurs at about the time of weaning and mingling with other pigs. In order to

23 establish disease control strategies, it is important to understand the horizontal transmission of

24 PMWS and PCV2 in starter barns. In a transmission study, we have previously shown that pigs 
1 from PMWS-free herds developed PMWS following mingling with pigs with PMWS. PMWS

2 developed in the PMWS-free pigs after close contact (same pen), nose-to-nose contact (to pigs in

3 neighbouring pens) or no direct contact (pen across the aisle) (Kristensen et al., 2009). In the

4 present study, we specifically determined horizontal transmission of PCV2 and examined viral

5 dynamics in pigs from this transmission study to elucidate if PCV2, in addition to PMWS, was

6 transmitted from PMWS-affected pigs to non-affected pigs. This is important knowledge as it is

7 unclear if transmission of the disease PMWS coincide with transmission of PCV2. Horizontal

8 transmission of PCV2 was determined by studying the spread of different variants of PCV2 in the

9 research facility, while viral dynamics was examined by quantifying the viral load in serum at 10 different time points by real-time PCR.

2. Materials and methods

\subsection{Experimental design and sampling}

The PCV2 transmission study was performed with pigs collected from 6 different herds in Denmark as described elsewhere (Kristensen et al., 2009; study II). Four of the herds showed problems with PMWS and had mortalities from 5-15\%. All four herds were seropositive for PRRS (except herd E (figure 1)), PCV2 and mycoplasma (Kristensen et al., 2009). Two of the herds were free from PMWS and had mortalities of approx. 2\% (Kristensen et al., 2009). These two herds were seropositive for PCV2 and mycoplasma (Kristensen et al., 2009). From the four herds with PMWS, 27 pigs (6-11 weeks old) with clinical signs of PMWS (wasting and unthriftiness) were collected from each herd. From the two healthy herds, 144 pigs (4-5 weeks old) were collected from each herd. All the selected pigs from PMWS-affected herds (108 pigs) and 216 pigs from the non- 
1 affected herds were mingled in 4 compartments (Comp. 1-4) at the same farm (Figure 1). As on-site

2 controls, 18 of the selected pigs from the healthy herds were placed in a separate compartment

3 (Comp. 5, Figure 1). The pens in the compartments were separated by bars permitting the pigs to

4 have nose-to-nose contact. As off-site controls, 54 of the selected pigs from the healthy herds were

5 kept at a separate farm. The duration of the infection study was 46-48 days.

6 Blood samples were collected from all the pigs at arrival. In addition samples were collected three

7 weeks later and at the termination of the study. The blood samples were centrifuged and serum

8 stored at $-80^{\circ} \mathrm{C}$. Clinical signs were recorded continuously during the study period. Pigs showing

9 severe clinical signs referable to PMWS (wasting, unthriftines, dyspnoea and diarrhoea) were

10 euthanized and mesenterial lymph nodes collected at necropsy. The lymph nodes were frozen at -

$1120^{\circ} \mathrm{C}$. Pigs, from whom mesenterial lymph nodes were collected, achieved the full PMWS-

12 diagnosis if they together with the clinical signs showed characteristic histopathological lesions in

13 lymphoid tissue (lymphocyte depletion together with histiocytic infiltration and giant cell or 14 inclusion bodies) and detection of moderate to massive amount of PCV2 antigen by 15 immunofluorescence microscopy (Kristensen et al., 2009).

\subsection{PCV2 PCR amplification and sequencing}

19 DNA was extracted from mesenterial lymph nodes and serum using QIAamp DNA Mini Kit 20 (QIAGEN, Ballerup, Denmark) according to the manufacturer's instructions. The PCV2 genome 21 was PCR amplified in three overlapping reactions with the primer pairs listed in Table 1. The PCR 22 reactions were performed as previously described (Dupont et al., 2007). Occasionally the resulting 23 PCR products, as visualised by gel electrophoresis, showed unspecific amplification of genomic pig 24 DNA together with genomic PCV2 DNA. In these cases the PCR products were purified with a 
1 QIAquick PCR Purification Kit (QIAGEN) and PCR amplified once more with the nested primer

2 pairs listed in Table 1. The PCR products were sequenced on both strands with the sequencing

3 primers listed in Table 1. The sequence reactions were performed by Agowa (Germany).

4

$5 \quad$ 2.3. Sequence analysis

6

7 Complete PCV2 genomes were assembled using CromasPro version 1.33

8 (http://www.technelysium.com.au/ChromasPro.html) and aligned using ClustalX version 1.8.2

9 (http://www.pasteur.fr).

10

11 2.4. Real-time PCR

12

13 PCV2 was quantified by real-time PCR on serum samples obtained at arrival and at death or

14 termination of the experiment. Real-time PCR with PriProET chemistry was performed as 15 previously described (Hjulsager et al., 2008).

16

17 3. Results

18

19 3.1. Spread of PCV2

20

21 To investigate transmission of PMWS and PCV2, pigs with clinical symptoms of PMWS

22 originating from PMWS-affected herds were mingled with clinically healthy pigs originating from

23 non-affected herds on a research facility as shown in Figure 1. During the study period, 44 pigs out

24 of 324 (pigs in compartment 1-4) were diagnosed with PMWS as shown by clinical signs together 
1 with characteristic histopathological lesions in lymphoid tissue and PCV2 antigen detection by

2 immunofluorescence microscopy (data not shown). Thirty of the pigs came from PMWS-affected

3 herds, whereas, 14 came from non-affected herds. None of the healthy control pigs in compartment

$4 \quad 5$ and at the separate control farm were diagnosed with PMWS.

5 To obtain a more precise picture of PCV2-transmission in the compartments, full PCV2 genome

6 sequences were obtained from all 44 pigs that developed PMWS. PCV2 sequencing showed the

7 presence of 8 major variants of a PCV2 sequence (GenBank acc. nr. EF565344) belonging to genotype PCV-2b (Segalés et al., 2008) corresponding to genotype 1 (Olvera et al., 2007). Single

9 base differences separating the 8 variants served as specific markers, which could be used to track

10 the spread of each PCV2 variant among pigs in the experiment. The 8 PCV2-variants were

11 distributed in the compartments so that 2-3 different variants were characteristic to each compartment (Table 2).

13 The placement of each pig that developed PMWS generally showed that pigs carrying the same

14 variant of PCV2 were placed in the same pen or in neighbouring pens (Fig. 2). Of the 14 pigs from

15 healthy herds that developed PMWS, 8 were placed in close contact (same pen) with pigs from

16 PMWS-affected herds, which developed PMWS with the same variant of PCV2. Four of the pigs developed PMWS with the same variant of PCV2 as pigs from PMWS-affected herds placed in neighbouring pens. In two cases, pigs from healthy herds developed PMWS with a PCV2 variant

19 characteristic to another compartment (PCV2 variant 3 and 4).

20 Development of PMWS in the pigs during this experiment may either have been caused by the

21 variant of PCV2, which the animals carried when they entered the research facility, or the animals may have been infected with PCV2 from other pigs in the research facility. To distinguish between these two possibilities, PCV2 was sequenced from the pigs shown in table 3 at arrival to the research facility (serum samples) and compared to PCV2 sequences obtained when they died or 
1 were euthanized (lymph nodes). As shown in Table 3, pigs from PMWS affected herds developed

2 PMWS with the same variant of PCV2 that they carried at arrival, except for pig number 17. All

3 pigs from non-affected herds developed PMWS caused by other variants of PCV2 than they carried

4 when entering the research facility (Table 3). Interestingly, these PCV2-variants were identical to

5 those found in pigs from PMWS-affected herds placed in the same pen or neighbouring pens (Table 62 and Fig. 2).

\subsection{Study of PCV2 dynamics by real-time PCR}

10 To study the relationship between PMWS status and PCV2 titer in serum, real-time PCR was used

11 to quantify PCV2 in serum samples obtained at arrival to the research facility and again at death or 12 at the termination of the study (Fig. 3).

13 Pigs from PMWS-affected herds that recovered clinically during the study period (Fig. 3, A) had a 14 mean PCV2 titer below $10^{8}$ copies/ml serum at arrival declining by two log units during the study 15 period. In contrast, pigs from PMWS-affected herds that died from PMWS during the study period 16 (Fig. 3, B) had a mean PCV2 titer above $10^{9}$ copies $/ \mathrm{ml}$ serum at arrival. This high titer was maintained until death.

18 Healthy pigs from non-affected herds had a mean PCV2 titer below $10^{5}$ copies $/ \mathrm{ml}$ serum at arrival.

19 Pigs that remained healthy during the study (Fig. 3, C) had a mean PCV2 titer below $10^{7}$ copies $/ \mathrm{ml}$ 20 serum at the end of the study, whereas pigs that were diagnosed with PMWS (Fig. 3, D) obtained a 21 mean PCV2 titer in serum at $10^{10}$ copies $/ \mathrm{ml}$.

22 None of the healthy pigs from non-affected herds placed as on-site controls in compartment 5 (Fig.

23 1) and as off-site controls on a separate control farm developed PMWS. At arrival the mean PCV2 24 titer in these pigs were below $10^{4}$ copies/ml serum. Interestingly, at the end of the study, the mean 
1 PCV2 titer in the on-site control pigs increased to $10^{9}$ copies/ml serum (Fig. 3, E), whereas the mean PCV2 titer in the off-site control pigs declined to below the detection limit (Fig. 3, F).

\section{Discussion}

6 To our knowledge this is the first study that has examined horizontal transmission of distinct variants of PCV2 in a research facility where pigs with clinical signs of PMWS were mingled with healthy pigs. The closest is an observation by Grau-Roma et al. (2008a) where two sows located on

9 the same farm and in the same room were shown to contain identical PCV2 sequences, indicating 10 horizontal transmission of PCV2.

11 In the present study $13.6 \%$ of the pigs in compartment $1-4$ were diagnosed with PMWS. Of the 12 pigs from PMWS-affected herds, $28 \%$ acquired PMWS, whereas only $6.5 \%$ of the pigs from non-

13 affected herds acquired PMWS. The significantly higher rate of PMWS in pigs from PMWS14 affected herds is most likely due to the fact that these pigs were selected based on clinical signs of 15 PMWS.

16 By comparison of PCV2 sequences obtained from selected pigs at arrival to the research facility and again at death caused by PMWS, it was concluded that pigs from non-affected herds developed PMWS with a PCV2 variant coming from pigs belonging to PMWS-affected herds. In contrast, pigs

19 from PMWS-affected herds generally developed PMWS with the same variant of PCV2 as they carried when entering the research facility. Pig number 17 (Table 3) developed PMWS with a PCV2

21 variant slightly different from the variant carried at entrance to the research facility. This variant was not detected in other pigs and possible was a result of mutation during the study period. The reason why pigs from non-affected herds were infected with PCV2 from pigs from PMWS-affected

24 herds is probably connected to an at least $10^{3}$ times higher mean titer of PCV2 in serum from pigs 
1 from PMWS-affected herds as compared to pigs from non-affected herds at the start of the

2 experiment. Like this, there has been found a positive and significant correlation between PCV2

3 viral loads present in serum, and in nasal and rectal swabs (Grau-Roma et al., 2008b).

4 By studying the spread of different variants of PCV2 in the research facility, we found that PCV2

5 primarily was transmitted to pigs from non-affected herds through direct contact (8 out of 14 pigs) and nose-to-nose contact (4 out of 14 pigs). More seldom PCV2 was transmitted without physical contact of the pigs ( 2 out of 14 pigs). We speculate that PCV2 in these two cases was transmitted by air or by personnel. Transmission by air was minimized by never open doors into two or more compartments at the same time, whereas transmission of PCV2 by personnel was minimized by

10 changing clothes and boots before entering the pens and by using disposable gloves. In conclusion,

11 our results support the notion that direct contact with faeces and urine, and frequent nose contact are 12 the most important factors for spreading of PCV2. This is in agreement with detection of PCV2 in 13 nasal, faecal and urinary swabs (Segalés et al., 2005b; Shibata et al., 2003).

14 Pigs from PMWS-affected herds that recovered clinically and survived throughout the study period 15 had at arrival a mean titer of PCV2 100 times lower than pigs from PMWS-affected herds that got a 16 confirmed diagnosis of PMWS. At termination of the study, the PCV2 titer in these pigs was 17 declined even further indicating that these pigs were recovering from the PCV2 infection. In 18 contrast, pigs diagnosed with PMWS maintained a high mean PCV2 titer in serum until death 19 supporting that these pigs did not have the ability to recover from the PCV2 infection.

20 The mean PCV2 titer in pigs from non-affected herds that remained healthy during the transmission 21 study increased 65 times during the study period, whereas the PCV2 titer increased $10^{6}$ times in 22 pigs that were diagnosed with PMWS. This strongly indicates that all pigs were affected by PCV2 23 infection but pigs able to control the PCV2-infection stayed healthy. 
1 Pigs from healthy herds kept at the off-site control farm had a mean PCV2 titer around the detection

2 limit at arrival and we did not see any increase in the PCV2 titer in these pigs during the study

3 period. In contrast, we observed a $10^{5}$ time increase in the mean PCV2 titer in the on-site control

4 pigs. This considerable increase in mean PCV2 titer was coupled to 2 out of 14 pigs with a PCV2

5 titer of $10^{9}-10^{10}$ copies pr. ml serum (Data not shown) at the end of the study. The rest of the on-site

6 control pigs had a PCV2-titer below $10^{8}$ copies pr. $\mathrm{ml}$ serum. We speculate that these two pigs

7 would have developed PMWS if the study had continued. These results strongly indicate that the on-site control pigs were affected by the PMWS-status of the research facility; despite they were

9 kept isolated in compartment 5. We sequenced PCV2 from 3 on-site control pigs with a high PCV2

10 titer to clarify if PCV2 was transmitted to them from the other compartments (data not shown). At

11 the start of the transmission study, PCV2 was undetectable in these pigs, but at the end of the study

12 all pigs harboured variant 3 . PCV2 variant 3 was characteristic to PMWS-affected pigs in

13 compartment 2 (Fig. 2) supporting transmission of PCV2 by air or by personnel. However, the

14 mean PCV2-titer in the on-site control pigs increased more slowly than in the healthy pigs mingled

15 with pigs from PMWS-affected herds as determined by quantification of PCV2 in serum samples

16 collected after three weeks (data not shown).

17 Pigs from both PMWS-affected herds and non-affected herds that were diagnosed with PMWS had

18 a very variable PCV2 titer in serum at death ranging from $10^{6}-10^{11}$ copies $/ \mathrm{ml}$ (data not shown).

19 Most often, however, the PCV2 titer in serum was above $10^{7}$ copies $/ \mathrm{ml}$, the previously suggested

20 threshold for the PMWS diagnosis (Brunborg et al., 2004; Olvera et al., 2004; Segalés et al., 2005b;

21 Grau-Roma et al., 2008b). Interestingly, all pigs in this study from both PMWS-affected herds and

22 non-affected herds (except the two on-site control pigs) that were not diagnosed with PMWS had a

23 PCV2 titer below $5 \times 10^{8}$ copies $/ \mathrm{ml}$ serum at all time points (data not shown). The window between

$2410^{7}$ and $5 \times 10^{8}$ copies of PCV2 pr ml serum is therefore particular interesting, as it seems like the 
1 pigs are wobbling between getting control over the PCV2-infection in this window or die from 2 PMWS.

3 In conclusion, this study shows that transmission of PMWS from PMWS-affected pigs to healthy

4 pigs coincide with transmission of PCV2 variants hosted by the PMWS-affected pigs. Furthermore,

5 the study confirms that PCV2/PMWS are readily transmitted from diseased to non-diseased pigs by

6 direct and indirect contact. In addition the results indicate that PCV2 is transmissible to healthy pigs

7 isolated on a farm habouring PMWS-affected pigs. These findings may have important implications

8 for herds that experience outbreak of PMWS since very strong bio-security barriers between

9 sections are needed to avoid spread of the virus/disease.

11 Acknowledgement

12

13 We thank Katja Kristensen, Hue Tran and Helene Nielsen for technical assistance. Financial 14 support to this study was given by EU (contract no. 513928) and The Research Counsil for Food, 15 Fisheries and Agri Business (grant no. 23-04-0242).

References

19 Albina, E., Truong, C., Hutet, E., Blanchard, P., Cariolet, R., L'Hospitalier, R., Mahe, D., Allee, C., Morvan, H., Amenna, N., Le, D.M., Madec, F., Jestin, A., 2001. An experimental model for post-weaning multisystemic wasting syndrome (PMWS) in growing piglets. J. Comp Pathol. 125, 292-303. 
1 Bolin, S.R., Stoffregen, W.C., Nayar, G.P., Hamel, A.L., 2001. Postweaning multisystemic wasting syndrome induced after experimental inoculation of cesarean-derived, colostrum-deprived piglets with type 2 porcine circovirus. J. Vet. Diagn. Invest 13, 185-194.

Brunborg, I.M., Moldal, T., Jonassen, C.M., 2004. Quantitation of porcine circovirus type 2 isolated from serum/plasma and tissue samples of healthy pigs and pigs with postweaning multisystemic wasting syndrome using a TaqMan-based real-time PCR. J. Virol. Methods $122,171-178$.

Chae, C., 2004. Postweaning multisystemic wasting syndrome: a review of aetiology, diagnosis and pathology. Vet. J. 168, 41-49.

Dupont, K., Nielsen, E.O., Bækbo P., Larsen L.E., 2007. Genomic analysis of PCV2 isolates from Danish archives and a current PMWS case-control study supports a shift in genotypes with time. Vet. Microbiol. 128, 56-64.

Grau-Roma, L., Crisci, E., Sibila, M., López-Soria, S., Nofrarias, M., Cortey, M., Fraile, L., Olvera, A., Segalés, J., 2008a. A proposal on porcine circovirus type 2 (PCV2) genotype definition and their relation with postweaning multisystemic wasting syndrome (PMWS) occurrence. Vet Microbiol.128, 23-35.

Grau-Roma, L., Hjulsager, C.K., Sibila, M., Kristensen, C.S., López-Soria, S., Enøe, C., Casal, J., Bøtner, A., Nofrarías, M., Bille-Hansen, V., Fraile, L., Baekbo, P., Segalés, J., Larsen, L.E., 2008b. Infection, excretion and seroconversion dynamics of porcine circovirus type 2 (PCV2) in pigs from postweaning multisystemic wasting syndrome (PMWS) affected farms in Spain and Denmark. Doi:10.1016/j.vetmic.2008.10.007 
1 Harding, J.C.S., Clark, E.G., 1997. Recognizing and diagnosing postweaning multisystemic wasting syndrome (PMWS). Swine Health and Prod. 5, 201-203.

Hjulsager, C., Grau-Roma, L., Sibila, M., Enøe, C., Larsen, L.E., Segalés, J., 2008. Inter-laboratory and inter-assay comparison on two real-time PCR techniques for quantification of PCV2 nucleic acid extracted from field samples. Doi:10.1016/j.vetmic.2008.06.014

Krakowka, S., Ellis, J.A., Meehan, B., Kennedy, S., McNeilly, F., Allan, G., 2000. Viral wasting

Kristensen, C.S., Bækbo, P., Bille-Hansen, V., Bøtner, A., Vigre, H., Enøe, C., and Larsen, L.E., syndrome of swine: experimental reproduction of postweaning multisystemic wasting syndrome in gnotobiotic swine by coinfection with porcine circovirus 2 and porcine parvovirus. Vet. Pathol. 37, 254-263. 2009. Induction of Porcine Postweaning Multisystemic Wasting Syndrome (PMWS) in pigs from PMWS unaffected herds following mingling with pigs from PMWS affected herds. Submitted to Vet. Microbiol. Doi: 10.1016/j.vetmic.2009.04.004

Liu, Q., Wang, L., Willson, P., Babiuk, L.A., 2000. Quantitative, competitive PCR analysis of porcine circovirus DNA in serum from pigs with postweaning multisystemic wasting syndrome. J. Clin. Microbiol. 38, 3474-3477.

Magar, R., Larochelle, R., Thibault, S., Lamontagne, L., 2000. Experimental transmission of porcine circovirus type 2 (PCV2) in weaned pigs: a sequential study. J. Comp Pathol. 123, 258-269.

Olvera, A., Cortey, M., Segalés, J., 2007. Molecular evolution of porcine circovirus type 2 genomes: phylogeny and clonality. Virology 357, 175-185. 
1 Olvera, A., Sibila, M., Calsamiglia, M., Segalés, J., Domingo, M., 2004. Comparison of porcine circovirus type 2 load in serum quantified by a real time PCR in postweaning multisystemic wasting syndrome and porcine dermatitis and nephropathy syndrome naturally affected pigs. J. Virol. Methods 117, 75-80.

Rovira, A., Balasch, M., Segalés, J., Garcia, L., Plana-Duran, J., Rosell, C., Ellerbrok, H., Mankertz, A., Domingo, M., 2002. Experimental inoculation of conventional pigs with porcine reproductive and respiratory syndrome virus and porcine circovirus 2. J. Virol. 76, 3232-3239.

Segalés J., Olvera A., Grau-Roma L., Charreyre C., Nauwynck H., Larsen L., Dupont K., McCullough K., Ellis J., Krakowka S., Mankertz A., Fredholm M., Fossum C., Timmusk S., Stockhofe-Zurwieden N., Beattie V., Armstrong D., Grassland B., Baekbo P., Allan, G., 2008. PCV-2 genotype definition and nomenclature. Vet Rec.162, 867-868.

Segalés, J., Allan, G.M., Domingo, M., 2005a. Porcine circovirus diseases. Anim Health Res. Rev. $6,119-142$.

Segalés, J., Calsamiglia, M., Olvera, A., Sibila, M., Badiella, L., Domingo, M., $2005 b$. Quantification of porcine circovirus type 2 (PCV2) DNA in serum and tonsillar, nasal, tracheo-bronchial, urinary and faecal swabs of pigs with and without postweaning multisystemic wasting syndrome (PMWS). Vet. Microbiol. 111, 223-229.

Segalés, J., Domingo, M., 2002. Postweaning multisystemic wasting syndrome (PMWS) in pigs. A review. Vet. Q. 24, 109-124.

Shibata, I., Okuda, Y., Yazawa, S., Ono, M., Sasaki, T., Itagaki, M., Nakajima, N., Okabe, Y., Hidejima, I., 2003. PCR detection of porcine circovirus type 2 DNA in whole blood, serum, 
oropharyngeal swab, nasal swab, and feces from experimentally infected pigs and field cases. J. Vet. Med. Sci. 65, 405-408.

3

4 
Table 1

2 Sequences of PCR and sequencing primers. Primer positions are indicated relatively to a reference

3 strain with the GenBank accession number EF565344.

4

$5 \quad$ Tabel 2

6 Position of base differences identified in PCV2 genomes isolated from pigs that developed PMWS as compared to a reference strain with GenBank accession number EF565344. Pigs originating from herds with PMWS were from herd hdE-H, whereas, pigs originating from non-affected herds were

9 from herd hd3 and hd4.

$10 \quad{ }^{1}$ Compartment, see Fig. 1.

12 Table 3

13 Position of base differences identified in PCV2 genomes isolated in this study as compared to a

14 reference strain with GenBank accession number EF565344. The PCV2 genomes were isolated

15 from serum collected before mingling of the pigs (arrival) and from lymph nodes from the same 16 pigs after they developed PMWS (termination).

18 Fig. 1. The research facility used in the PCV2 transmission study. The pigs used in the study were

19 collected from four PMWS affected herds (herd E-H) and two non-affected herds (herd 3 and 4).

20 Pigs from the PMWS-affected herds $(+)$ were mingled with pigs from the non-affected herds $(-)$ in 21 pens as shown in the figure. The number of pigs in each pen is indicated. Bars, permitting the pigs 22 to have nose-to-nose contact, separated the pens. 
1 Fig. 2. Placement of pigs that developed PMWS. Closed circles indicate pigs from PMWS affected

2 herds (herd E-H). Open circles indicate pigs from non-affected herds. Each figure of the research

3 facility shows the placement of pigs containing a distinct PCV2 variant (1-8).

4

5 Fig. 3. PCV2 load mean and confidence interval in serum of pigs from PMWS-affected herds and

6 non-affected herds at arrival (white bars) and at death or end of study (black bars). n: number of

7 animals. The detection limit in the real-time PCR was $10^{3}$ PCV2 DNA copies $/ \mathrm{ml}$ serum. A: Pigs

8 showing clinical signs of PMWS at arrival. At the end of the study all the pigs were recovered

9 clinically. B: Pigs showing clinical signs of PMWS at arrival. All the pigs died early in the study

10 and were diagnosed with PMWS clinically as well as histopathologically. C: Healthy pigs without

11 clinical signs of PMWS at arrival. At the end of the study they still showed no clinical signs of

12 PMWS. D: Healthy pigs without clinical signs of PMWS at arrival. All pigs died late in the study

13 and were diagnosed with PMWS clinically as well as histopathologically. E: Healthy pigs without

14 clinical signs of PMWS placed as on-site controls in compartment 5 (Fig. 1). All pigs stayed

15 clinical PMWS-free during the study. F: Healthy pigs without clinical signs of PMWS placed as

16 off-site controls on a separate control farm. All pigs stayed clinical PMWS-free during the study. 


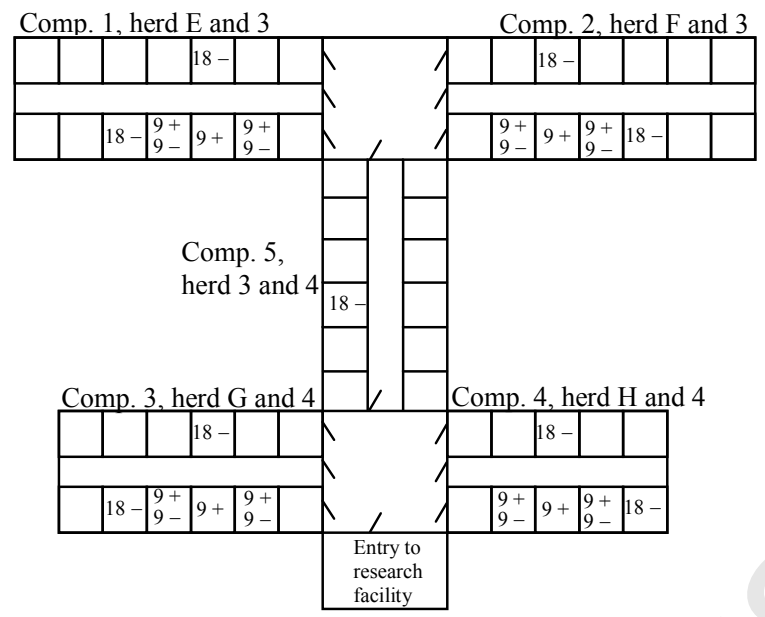


1.

3.
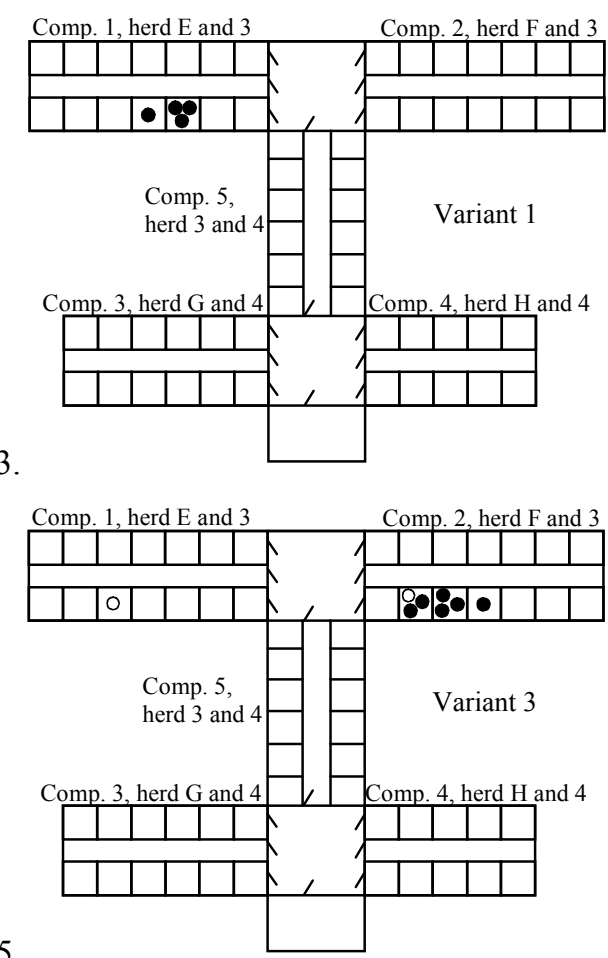

5.

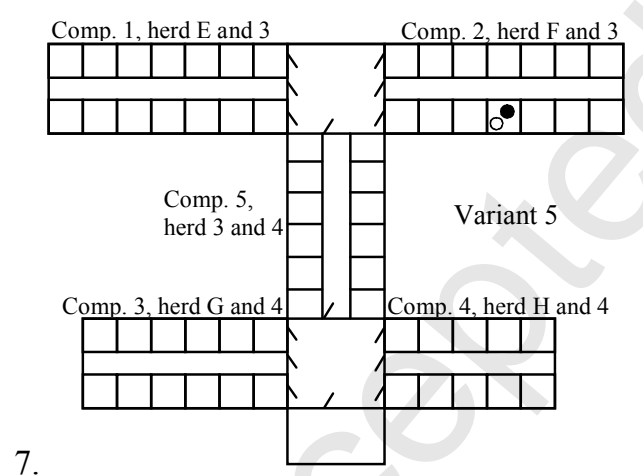

7.

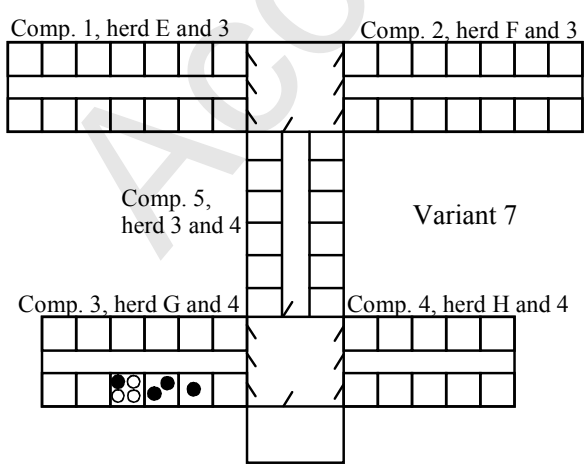

2.

4.

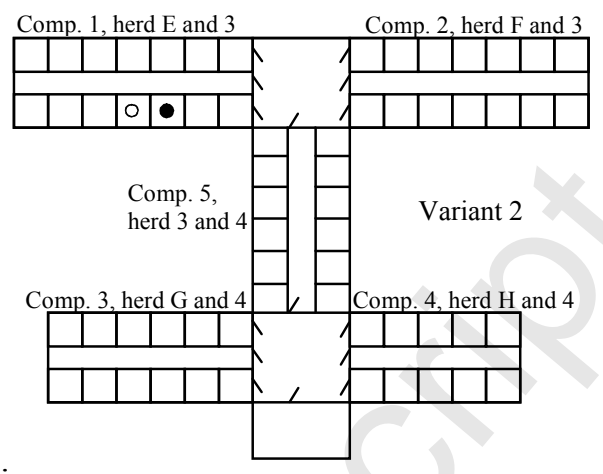

6.
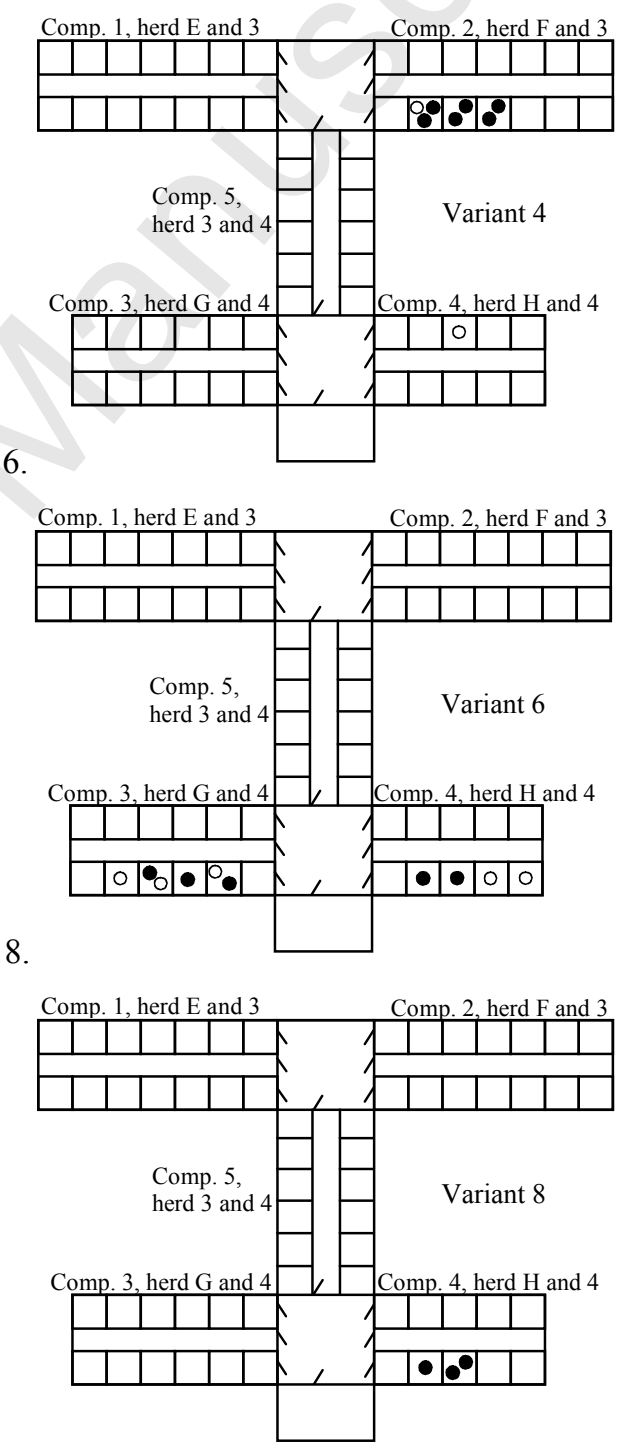


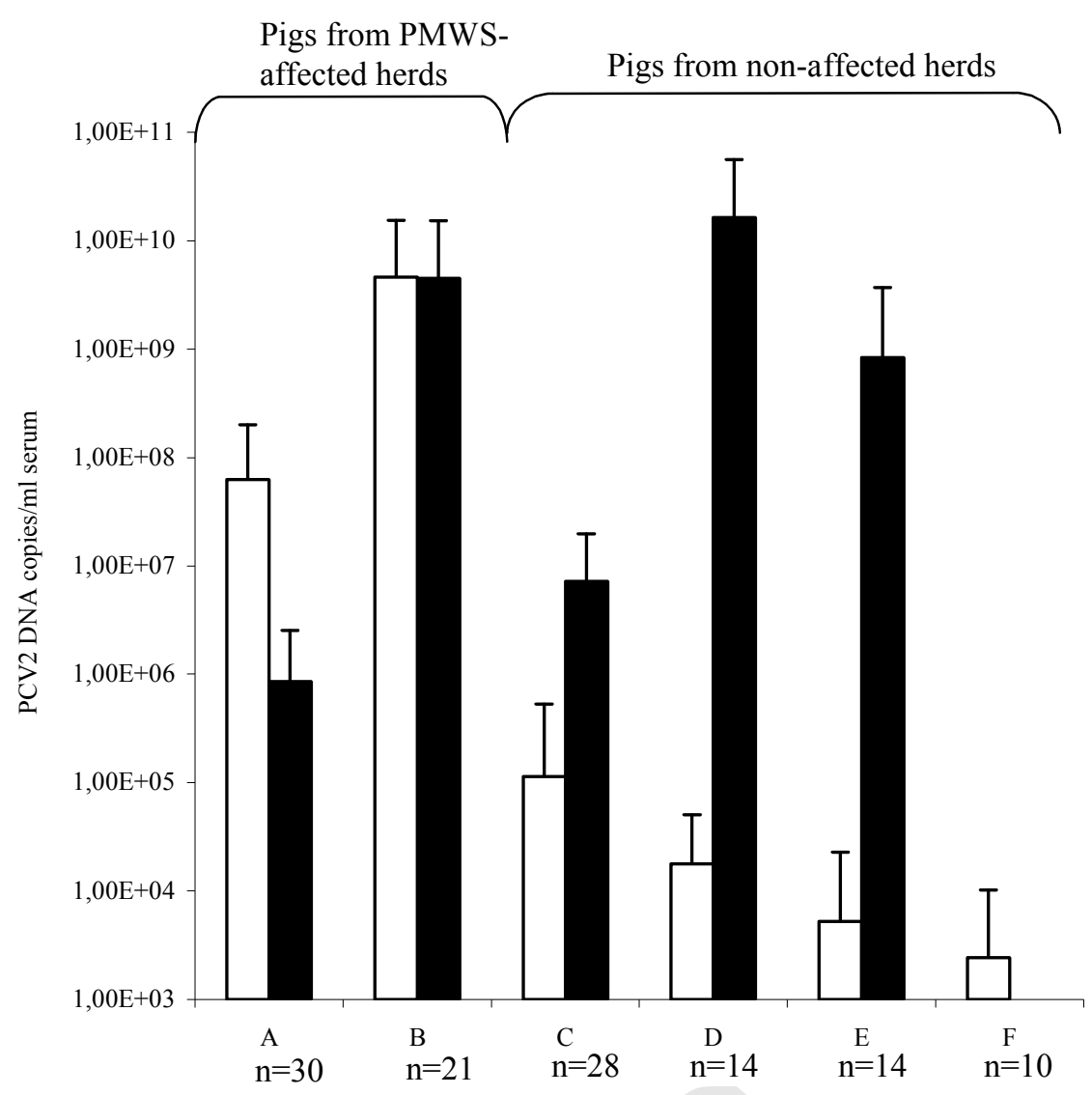




\begin{tabular}{|c|c|c|c|c|}
\hline & $\begin{array}{c}\text { Position } \\
\text { (nt) }\end{array}$ & Sequence $\left(5^{\prime} \rightarrow 3^{\prime}\right)$ & $\begin{array}{c}\text { Fragment length } \\
\text { (bp) }\end{array}$ & Reference \\
\hline \multicolumn{5}{|l|}{ PCR } \\
\hline PCV2-1for & $121-137$ & CTTCCGAAGACGAGCGC & 791 & Dupont et al., 2007 \\
\hline PCV2-1rev & $912-890$ & TAGCATTCTTCCAAAATACCAAG & & Dupont et al., 2007 \\
\hline PCV2-2for & $1308-1327$ & GTTTACATAGGGGTCATAGG & 713 & Dupont et al., 2007 \\
\hline PCV2-2rev & $253-233$ & TGCTTCTTCACAAAATTAGCG & & Dupont et al., 2007 \\
\hline PCV2-3for & $760-782$ & TAGAGACTAAAGGTGGAACTGTA & 781 & Dupont et al., 2007 \\
\hline PCV2-3rev & $1541-1524$ & TCCTGGGCGGTGGACATG & & Dupont et al., 2007 \\
\hline \multicolumn{5}{|l|}{ Nested PCR } \\
\hline NestPCV2-1 for & $131-150$ & CGAGCGCAAGAAAATACGGG & 758 & This study \\
\hline NestPCV2-1rev & $889-867$ & GAAGTAATCCTCCGATAGAGAGC & & This study \\
\hline NestPCV2-2for & $1348-1372$ & ACAAAGTTATCATCTAGAATAACAG & 659 & This study \\
\hline NestPCV2-2rev & $239-222$ & ATTAGCGAACCCCTGGAG & & This study \\
\hline NestPCV2-3 for & $780-799$ & GTACCTTTTTTGGCCCGCAG & 688 & This study \\
\hline NestPCV2-3rev & $1468-1446$ & CTGTACCCTTTGAATACTACAGA & & This study \\
\hline \multicolumn{5}{|l|}{ Sequencing } \\
\hline SeqPCV2-1for & $149-171$ & GGATCTTCCAATATCCСТАTTTG & & Dupont et al., 2007 \\
\hline SeqPCV2-1rev & $871-854$ & AGAGCTTCTACAGCTGGG & & Dupont et al., 2007 \\
\hline SeqPCV2-2for & $1370-1387$ & CAGCACTGGAGCCCACTC & & Dupont et al., 2007 \\
\hline SeqPCV2-2rev & $221-203$ & GTGAGGTGTTCGTCCTTCC & & Dupont et al., 2007 \\
\hline SeqPCV2-3for & $799-819$ & GTATTCTGATTACCAGCAATC & & Dupont et al., 2007 \\
\hline SeqPCV2-3rev & $1451-1430$ & TACAGAATAAGAAAGGTTAAGG & & Dupont et al., 2007 \\
\hline
\end{tabular}




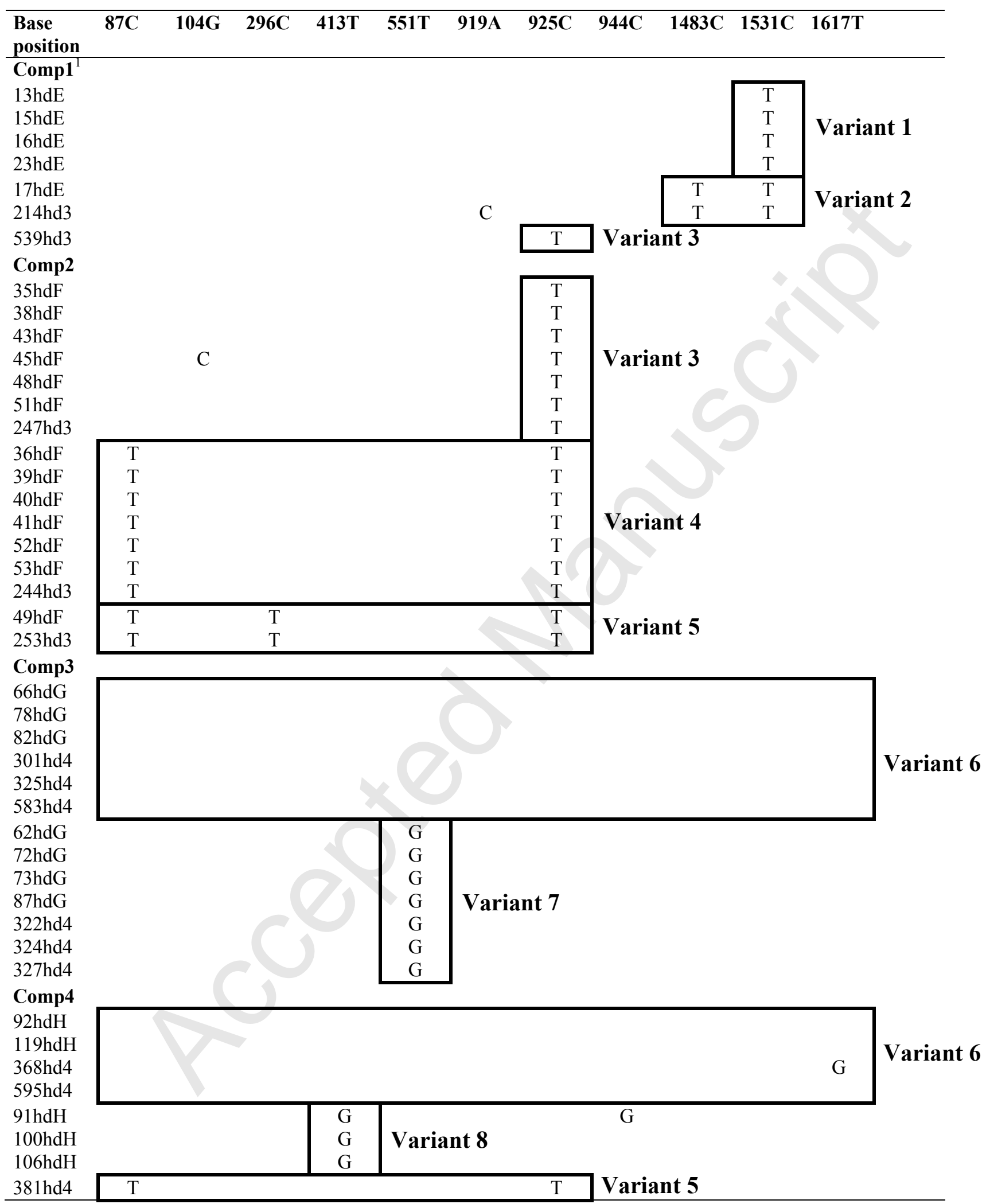




\begin{tabular}{|c|c|c|c|c|c|c|c|}
\hline \multicolumn{8}{|c|}{$\begin{array}{l}\text { Base position } 87 \mathrm{C} \\
\text { Pigs from herds with } \\
\text { PMWS }\end{array}$} \\
\hline \multicolumn{8}{|c|}{$\begin{array}{l}\text { Pigs from herds with } \\
\text { PMWS }\end{array}$} \\
\hline 17arrival & & & & & & & $\mathrm{T}$ \\
\hline 17termination & & & & & & $\mathrm{T}$ & $\mathrm{T}$ \\
\hline 35arrival & & & & & $\mathrm{T}$ & & \\
\hline 35termination & & & & & $\mathrm{T}$ & & \\
\hline 36arrival & $\mathrm{T}$ & & & & $\mathrm{T}$ & & \\
\hline 36termination & $\mathrm{T}$ & & & & $\mathrm{T}$ & & \\
\hline $\begin{array}{l}\text { 66arrival } \\
\text { 66termination }\end{array}$ & & & & & & & \\
\hline $\begin{array}{l}\text { 119arrival } \\
119 \text { termination }\end{array}$ & & & & & & & \\
\hline
\end{tabular}

Pigs from non-affected herds

214arrival

214termination

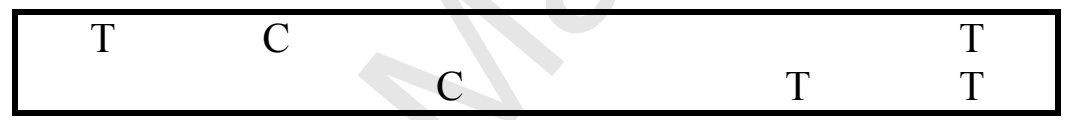

244arrival

244termination

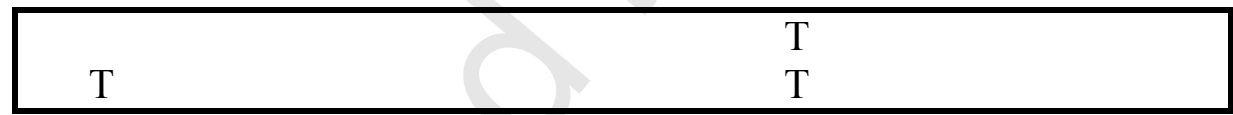

583arrival 583termination 